\title{
Bir İl Merkezinde Yaşayan Bireylerin Ruh Sağlığı Okuryazarlığının İncelenmesi
}

Investigation of Mental Health Literacy of Individuals Living In A City Center

\section{Hilal SEKİ ÖZ[1]}

Başvuru Tarihi:15 Eylül 2021

Kabul Tarihi: 15 Ekim 2021

Ruh sağlığı okuryazarlığı bireyin ruhsal hastalıkları anlama, tanıma ve yönetmedeki yetkinliği olarak tanımlanabilir. Toplum ruh sağlığını koruma ve geliştirmede önemli olan bu kavrama yönelik ülkemizde yeterli sayıda araştırma olmadığı görülmektedir. Tanımlayıcı türde yapılan bu araştırmayla bir il merkezinde yaşayan bireylerin ruh sağlığı okuryazarlı̆̆ı düzeyinin incelenmesi amaçlanmıştır. İç Anadolu'da bir il merkezinde yaşayan 388 bireye gelişigüzel kartopu yöntemiyle ulaşılmış, araştırma verileri çevirimiçi form ile toplanmıştır. Veriler için Tanıtıcı Bilgi Formu ve Ruh Sağlığı Okuryazarlığı Ölçeği kullanılmıştır. Veri analizinde tanımlayıcı istatistikler, Bağımsız Örneklemlerde t Testi, Tek Yönlü Varyans Analizi (ANOVA) ve Tukey testi yapılmıştır. Araştırmada bireylerin Bilgi Odaklı alt boyut puan ortalaması 7.20 \pm 2.39 , İnanç Odaklı alt boyutu 4.76 \pm 1.76 , Kaynak Odaklı alt boyutu $2.80 \pm 1.25$ ve ölçek toplamının $14.76 \pm 3.67$ olduğu; cinsiyetin, eğitim düzeyinin, çalışma durumunun, ruhsal konulara ilgili olmanın ve ruhsal hastalığı olan bireyi tanımanın önemli farklılık yarattığı saptanmıștır $(\mathrm{p}<0.05)$. Araștırmada yaș, medeni durum, ekonomik durum ve kronik hastalığa sahip olmanın ise önemli bir fark yaratmadığı bulunmuştur ( $p>0.05)$. Ölçek maddelerinden alınan ortalama puan incelendiğinde şizofreni, depresyon, hastalık oluşumu, intihar, iyileşme, tedaviler ve hizmet kullanımına yönelik maddelerin diğerlerine göre daha düşük puan aldığı görülmüştür. Araştırma sonucunda katılımcıların ruh sağlığı okuyazarlığının yüksek düzeyde olduğu ve sosyodemografik değișkenlerden etkilendiği saptanmıș olup, ruh sağlığı okuryazarlığının incelendiği ileri düzey araștırmalar önerilir.

Anahtar Kelimeler: ruh să̆lı̆̆ı, ruh sağlı̆̆ı okuryazarlı̆̆ı, sağlık okuryazarlı̆̆ı

Received Date:15 September 2021

Mental health literacy can be defined as an individual's competence in understanding, recognizing, and managing mental illnesses. It is seen that there is not enough research in our country on this concept, which is important in protecting and improving community mental health. With this descriptive study, it was aimed to examine the mental health literacy level of individuals living in a city center. 388 individuals living in a city center in Central Anatolia were reached by random snowball method, and the research data were collected with an online form. Introductory Information Form and Mental Health Literacy Scale were used for the data. Descriptive statistics, Independent Samples t-Test, One-Way ANOVA and Tukey's test were used in data analysis. In the study, the Knowledgeoriented sub-scale mean score of the individuals was 7.20 \pm 2.39 ; the Belief-oriented sub-scale was $4.76 \pm 1.76$, the Resource-oriented sub-scale was $2.80 \pm 1.25$, and the total scale was $14.76 \pm 3.67$, and gender, education level, working status, being interested in mental issues and knowing the individual with mental illness made a significant difference $(\mathrm{p}<0.05)$. In the study, it was found that age, marital status, economic status and having a chronic disease did not make a significant difference $(\mathrm{p}>0.05)$. When the items of the scale were examined, it was seen that the items related to schizophrenia, depression, disease occurrence, suicide, recovery, treatments, and service use had lower scores than the others. As a result of the research, it was determined that the participants had a high level of mental health literacy and were affected by sociodemographic variables, and advanced studies examining mental health literacy are recommended.

Keywords: mental health, mental health literacy, health literacy 660-675. https://doi.org/10.47793/hp.993929 


\section{GíRiș}

$\mathrm{R}$ uh sağlığı ile ilgili sorunların artıșı tüm dünya için bir endișe kaynağı olabilmektedir. Dünya Sağlık Örgütü'ne (DSÖ) (2011) göre, her dört kişiden biri yaşamı boyunca bir nöropsikiyatrik bozukluktan etkilenecektir. Türkiye nüfusunu yansıtan ruhsal hastalıklarla ilgili ilk geniş çaplı araştırma olan Ruh Sağlığı Profili çalışmasında ruhsal hastalıkların ülkemizdeki yaygınlığının \%17,2 olduğu, ruhsal hastalığı olan bireylerin sadece \%14'ünün tedavi için başvurduğu bildirilmiştir (Kılıç, 1998). Yardım arama davranışında özellikle kişinin ruhsal hastalıklara ve tedavilere yönelik bilgi, tutum ve inançları belirleyici olurken, toplumun ruhsal hastalığı olan bireylere negatif tutumu ve damgalama düzeyi de önemli bir etkiye sahiptir (Jung vd., 2016). Genel olarak toplumda ruhsal hastalıklar, fiziksel hastalıklardan daha fazla mitleri, streotipleri, olumsuz ve yanlış inançları barındıran, bu etkiyle erken tanı ve etkin tedavinin aksadığı hastalıklar olup, mücadelede ruh sağlığı okuryazarlığının gelişmesi kritik öneme sahiptir (Vimalanathan ve Furnham, 2019; Reavley ve Jorm, 2011).

Sağlık okuryazarlığının bir bileșeni olan ruh sağlığı okuryazarlığı bireysel ve toplumsal olarak sağlığı iyileștirme potansiyeliyle ruh sağlığının önemli bir belirleyicisidir (Özel, 2018). Ruh sağlığı okuryazarlığı "Ruhsal bozuklukların tanınmasına, yönetilmesine veya önlenmesine yardımcı olan bilgi ve inançları" ifade eden bir kavramdır (Jorm vd., 1997). Ülke sağlık politikalarını kapsayan bir bakış açısıyla toplumu oluşturan bireylerin ruhsal hastalıkların önlenmesi, tanınması, tedavi ve rehabilitasyonu hakkında bilgi sahibi olması ve damgalamanın azaltılarak yardım arama davranışının geliştirilmesi hedeflenir (Reavley ve Jorm, 2011). Düşük sağlık okuryazarlığına sahip hastalar, bilgileri iyi anlayamayacakları veya daha az koruyucu sağlık hizmeti alabilecekleri için yardım aramada dezavantajlı olabilmektedir (Naidu, 2008). Herhangi bir ruhsal hastalığı olan bireylerin yalnızca yarısının ruh sağlığı hizmetlerini kullandığı bildirilmekte (Bjørnsen vd., 2017) ve bu durum hastalığın ileri evresinde yardım aranması nedeniyle ruhsal hastalıkların kronikleşmesi ve ağırlaşması ile sonuçlanmaktadır (Kutcher vd., 2016; Li, 2012).

Bir toplumda ruh sağlığı okuryazarlığının artması olumsuz inançların değiş̧mesini sağlayarak ruh sağlığına ilişskin parametreleri olumlu etkileyecektir (Jorm, 2012). Ruh sağlığı hizmetlerinin faydalı ve etkili olduğuna inanan bireyler, yardım aramak için daha olumlu tutumlara sahip olacak ve ruh sağlığı hizmetlerini kullanmada daha istekli davranacaklardır (Jung vd., 2016). Aynı zamanda ruh sağlığı okuryazarlığının artışı ruhsal hastalığı olan bireylere yönelik davranışların da iyileşmesine, damgalamanın azalmasına ve ruhsal hastalığı olan bireylerin sağlık hizmetlerinden optimal düzeyde faydalanmasına imkân sunacaktır (Yap vd., 2012; Evans-Lacko vd., 2013; Corrigan vd., 2015). Bu bağlamda ruh sağlığı okuryazarlığının geliştirilmesi için 
öncelikle toplumdaki bireylerin ruhsal hastalıklara yönelik bakış açılarının tanımlanmasına yönelik bilgilere ihtiyaç duyulmaktadır.

\section{Araştırmanın Önemi}

Toplum ruh sağlığına yönelik hizmetlerin planlanmasında ve politikaların oluşturulmasında o toplumu oluşturan bireylerin ruhsal sorunlara yönelik bilgi, inanç ve tutumlarının tanımlanması ilk adımdır. Böylece bireylerin yaşına, cinsiyetine, yaşadığı yer gibi değişkenlere göre özel müdahaleler yapılarak bireylerin ve dolayısıyla toplumun ruh sağlığı okuryazarlığının artması sağlanacaktır. İlk kez 1997'de tanımlanan ruh sağlığı okuryazarlığı kavramı batılı ülkelerde daha erken dönemlerde incelenmeye başlanmış olsa da ülkemizde son yıllarda gündeme gelmiştir ve bu doğrultuda araştırmaların azlığı dikkat çeken düzeydedir. Yapılan alanyazın incelemesinde ülkemizde ölçek geliştirme çalışmaları dışında az sayıda araştırmanın yapıldığı görülmüştür (Öztaş ve Aydoğan, 2021; Göktaş vd., 2019). Ruh sağlığı okuryazarlığına yönelik araştırmalar ile destek duyan grupların belirlenmesi ve önceliklerin oluşturulması mümkün olacaktır.

\section{Araştırmanın Amacı}

Bu araştırma ile ülkemizde sınırlı sayıda araştırma yapılmış olan ruh sağlığı okuryazarlığı ile ilgili alanyazına katkı sağlamak ve bir il merkezinde yaşayan bireylerin ruh sağlığı okuryazarlığı düzeylerini incelenmek amaçlanmıştır. Bu doğrultuda araştırmada aşağıdaki sorulara yanıt aranmıştır;

1. Bir il merkezinde yaşayan bireylerin ruh sağlığı okuryazarlığı ne düzeydir?

2. Araştırmaya katılan bireylerin ruh sağlı̆̆ı okuryazarlı̆̆ı düzeyinde yaş, cinsiyet, eğitim durumu, medeni durumu, çalışma durumu, ekonomik durumu, kronik hastalık varlığı, ruhsal konulara ilgili olma ve ruhsal hastalığı olan bireyi tanıma durumu gibi tanıtıcı özelliklerine göre farklılık var mıdır?

3. Katılımcıların yanıtlarına göre ruh sağlığı okuryazarlığında hangi maddeler daha düşük puan almıştır?

\section{YÖNTEM}

\section{Araştırmanın Modeli}

Bu araştırma, bir durumun bulunması/görülmesi hakkında genel bir bakış açısı oluşturan araştırma türü olan tanımlayıcı türde (Karasar, 2017) tasarlanmış olup evreni belli örneklem hesaplaması ile örneklem büyüklüğü belirlenmiş ve gelişigüzel kartopu yöntemi (Baştürk ve Taştepe, 2013) ile veriler toplanmıştır. COVID-19 pandemisi nedeniyle veriler yüz yüze yöntemlerle toplanmamış, çevirimci form aracılığı ile katılımcılara ulaşılmıştır. 


\section{Araştırmanın Evreni ve Örneklemi}

Araştırmanın evrenini Kırşehir il merkezinde yaşayan 18-65 yaş aralığındaki yetişkin bireyler oluşturmaktadır. Kırşehir ili İç Anadolu bölgesinde yer alan, başkente yakın mesafede olan, farklı kültürleri barındıran küçük bir ildir. Kırşehir'de 2020-2021 yılı resmi nüfus kayıtlarına göre il merkezinde yaşayan birey sayısı 158.954 olarak bildirilmiştir (Kırşehir Nüfusu, 2021). Evreni belli örneklem hesaplaması kullanılarak \%95 güven düzeyi ve \%5 güven aralığı ile 383 kişi araştırmanın örneklemini oluşturmuştur. Araştırmaya dahil olma kriterleri; 18-65 yaş aralığında olma, il merkezinde yaşama ve araştırmaya katılmayı kabul etmedir.

\section{Veri Toplama Araçları}

Araştırma verileri Tanıtıcı Bilgi Formu ve Ruh Sağlığı Okuryazarlığı Ölçeği (RSOY) ile toplanmıştır.

Tanıtıcı Bilgi Formu. Araştırmacı tarafından hazırlanan bu form demografik verileri ve ruh sağlığına yönelik bazı bilgileri içeren toplam 11 sorudan oluşmaktadır.

Ruh Sağlığı Okuryazarlı̆̆ı Ölçeği (RSOY). Ruh sağlığı okuryazarlığı ölçeğinin orijinal formu Jung ve arkadaşları tarafından (2016) geliştirilmiştir. Ölçeğin Türkçe geçerlilikgüvenilirliği ise Göktaş ve arkadaşları tarafından (2019) yapılmıştır. RSOY Ölçeği 22 madde ve üç alt boyuttan oluşmaktadır. Bilgi Odaklı RSOY (ROSY-BO) alt boyutunda 10 madde, İnanç Odaklı RSOY (ROSY-İO) alt boyutunda 8 madde, Kaynak Odaklı RSOY (ROSY-KO) alt boyutunda 4 madde bulunmaktadır. Ölçeğin ilk iki alt boyutunda bulunan 18 madde altılı Likert tiptedir. RSOY-KO alt boyutunda bulunan dört madde ise "evet" ve "hayır" olarak cevaplanmaktadır. Ölçek değerlendirmesinde maddelere verilen "kesinlikle katılıyorum", "katılıyorum" ve "evet" cevabından bir puan, diğer cevaplardan puan alınmamaktadır. Ölçeğin 11,12,13,14,15,16,17 ve 18'inci maddeleri ters kodlanmaktadır. Ölçekten alınabilecek toplam puan 0-22 arasında değişmektedir (Göktaş vd., 2019). Ölçeğin geçerlik ve güvenirlik çalışmasında cronbach alfa katsayısı 0.71 , bu araştırmada ise 0,72 olarak hesaplanmıştır.

\section{Veri Toplama Süreci}

Araştırma verileri ölçek kullanım izni ve etik kurul izni alındıktan sonra çevirimiçi formun katılımcılara gönderilmesi ile 8-10 Eylül 2021 tarihlerinde toplanmıştır. Anket uygulamasında gelişigüzel kartopu yöntemi ile katılımcılara ulaşılmıştır. Katılımcıların uygulamayı tamamlamaları yaklaşık 10 dakika sürmüştür. Veri kaybı düşünülerek 410 kişi araştırmanın uygulamasına katılmıştır. Araştırmaya katılma kriterlerini karşılamayan (ilçe ya da köyde ikamet etme ve 18 yaş altında olma gibi) 22 katılımcı araştırma dışında bırakılmış ve araştırma 388 katılımcı ile tamamlanmıştır. 


\section{Verilerin Analizi}

$\mathrm{Bu}$ araştırmanın istatistiksel analizleri Statistical Package for the Social Sciences (SPSS) 25.0 for Windows programı ile yapılmıştır. Verilerin normal dağılıma uyup uymadığı ShapiroWilk-W Testi ile değerlendirilmiş ve normal dağılım gösterdiği saptanmıştır. Verilerin sunumunda tanımlayıcı istatistikler, analizler için Bağımsız Örneklemde t Testi, Tek Yönlü Varyans Analizi (ANOVA) ve ileri analizler için Tukey testi kullanılmıştır. İstatistiksel kararlarda p $<0,05$ önemli farklılığın göstergesi olarak kabul edilmiştir.

\section{Etik Onay}

Araştırmaya katılmadan önce araştırma hakkında detaylı bilgi içeren ve araştırmaya katılmanın gönüllülük esasına dayalı olduğunu bildiren bir açıklama çevirimiçi forma yerleștirilmiş ve katılımcılar onaylarını verdikten sonra anketin uygulaması başlatılmıștır. Helsinki Bildirgesine uygun olarak gerçekleştirilen araştırma için Kırşehir Ahi Evran Üniversitesi Girişimsel Olmayan Etik Kurulundan 07.09.2021/ 2021- 14/159 karar nosu ile etik onay alınmıştır.

\section{BULGULAR VE YORUM}

Araştırmaya katılan bireylerin tanıtıcı özelliklerine göre dağılımları incelendiğinde \%54.6'sının kadın, \%34.5'inin 18-25 yaş aralığında ve yaş ortalamasının 33.84ะ11.56 olduğu, \%59.8'i üniversite mezunu, \%50.7'si bekar ve \%59'unun bir işte çalıștığı görülmektedir. Katılımcıların çoğunluğunun ekonomik durumunu orta olarak değerlendirdiği, kronik hastalığı olmadığı ve ruh sağlığına yönelik konulara ilgi duydukları görülmüştür. Katılımcıların çoğunluğunun ruhsal hastalığa sahip bireyleri tanımadıkları belirlenmiş, tanıyanların ise en çok aileden veya akrabalarından olduğunu bildirmiştir (Tablo 1). 
Tablo 1

Katılımcıların tanıtıcı özelliklerine göre dağılımı (n=388)

\begin{tabular}{|c|c|c|c|}
\hline Değişkenler & & $\mathbf{n}$ & $\%$ \\
\hline \multirow{2}{*}{ Cinsiyet } & Erkek & 176 & 45.4 \\
\hline & Kadın & 212 & 54.6 \\
\hline \multirow{4}{*}{ Yaş } & $18-25$ & 134 & 34.5 \\
\hline & $26-34$ & 76 & 19.6 \\
\hline & $35-42$ & 88 & 22.7 \\
\hline & 43 ve üstü & 90 & 23.2 \\
\hline \multirow{4}{*}{ Eğitim durumu } & İlköğretim & 26 & 6.7 \\
\hline & Lise & 65 & 16.8 \\
\hline & Üniversite & 232 & 59.8 \\
\hline & Lisansüstü & 65 & 16.7 \\
\hline \multirow{2}{*}{ Medeni durum } & Bekar & 197 & 50.7 \\
\hline & Evli & 191 & 49.3 \\
\hline \multirow{4}{*}{ Çalışma durumu } & Çalışan & 229 & 59.0 \\
\hline & İş arayan & 22 & 5.7 \\
\hline & Öğrenci & 93 & 23.9 \\
\hline & Ev hanımı & 44 & 11.4 \\
\hline \multirow{3}{*}{ Ekonomik durumu } & Kötü & 111 & 28.6 \\
\hline & Orta & 191 & 49.2 \\
\hline & İyi & 86 & 22.2 \\
\hline \multirow{2}{*}{ Kronik hastalık varlığı } & Evet & 352 & 90.7 \\
\hline & Hayır & 36 & 9.3 \\
\hline \multirow{2}{*}{ Ruhsal sağlıkla ilgili konulara ilgisi olma } & Evet & 345 & 88.9 \\
\hline & Hayır & 43 & 21.1 \\
\hline \multirow{3}{*}{ Ruhsal hastalığı olan bireyi tanıma } & Hayır, tanımıyor & 258 & 66.5 \\
\hline & Evet, aile ya da akraba & 89 & 23.0 \\
\hline & Evet, arkadaş ya da komşu & 41 & 10.5 \\
\hline Yaş & Ort. \pm SS & \multicolumn{2}{|c|}{$33.84 \pm 11.56$} \\
\hline
\end{tabular}

Katılımcıların tanıtıcı özelliklerine göre RSOY ölçeği puan dağılımları ikili gruplar için Bağımsız Örneklemde t Testi, üç ve üstü gruplar için Tek Yönlü Varyans Analizi (ANOVA) testi ile incelenmiştir. RSOY-BO alt boyutunda erkek olanların, öğrenci olanların ve ruhsal hastalığı olan bireyi tanımayanların; RSOY-İO alt boyutunda erkek olanların, öğrenci olanların ve ruhsal sağlıkla ilgili konulara ilgisi olmayanların; RSOY-KO alt boyutunda ise ruhsal sağlıkla ilgili konulara ilgisi olmayanların puan ortalamalarının düşük düzeyde olduğu saptanmıştır $(\mathrm{p}<0.05)$. Tukey çoklu karşılaştırma testi sonucuna göre RSOY ölçek toplamında erkeklerin, lise mezunu olanların, öğrenci olanların, ruhsal sağlıkla ilgili konulara ilgisi olmayan ve ruhsal hastalı̆̆ı olan bireyi tanımayanların puan ortalamalarının düşük düzeyde olduğu bulunmuştur ( $\mathrm{p}<0.05)$ (Tablo 2). 
Tablo 2

Katılımcıların tanıtıcı özelliklerine göre RSOY alt boyut ve ölçek toplam puanları

\begin{tabular}{|c|c|c|c|c|c|c|c|c|}
\hline & \multicolumn{2}{|c|}{ Bilgi Odaklı RSOY } & \multicolumn{2}{|c|}{ İnanç Odaklı RSOY } & \multicolumn{2}{|c|}{ Kaynak Odaklı RSOY } & \multicolumn{2}{|c|}{ Ölçek Toplamı } \\
\hline & $\mathrm{X} \pm \mathrm{SD}$ & $\begin{array}{c}\text { Test } \\
\text { P }\end{array}$ & $\mathrm{X} \pm \mathrm{SD}$ & $\begin{array}{c}\text { Test } \\
\text { P }\end{array}$ & $\mathrm{X} \pm \mathrm{SD}$ & $\begin{array}{c}\text { Test } \\
\text { P }\end{array}$ & $\mathrm{X} \pm \mathrm{SD}$ & $\begin{array}{c}\text { Test } \\
\text { P }\end{array}$ \\
\hline \multicolumn{9}{|l|}{ Cinsiyet } \\
\hline Kadın & $7.51 \pm 2.26$ & \multirow{2}{*}{$\begin{aligned} \mathrm{t}= & -2.852 \\
& \mathbf{. 0 0 5}\end{aligned}$} & $4.93 \pm 1.69$ & \multirow{2}{*}{$\begin{aligned} t= & -2.108 \\
& .036\end{aligned}$} & $2.90 \pm 1.26$ & \multirow{2}{*}{$\begin{array}{c}\mathrm{t}=1.533 \\
.126\end{array}$} & $15.16 \pm 3.71$ & \multirow{2}{*}{$\begin{aligned} t= & -2.334 \\
& \mathbf{0 2 0}\end{aligned}$} \\
\hline Erkek & $6.82 \pm 2.49$ & & $4.55 \pm 1.82$ & & $2.71 \pm 1.25$ & & $14.28 \pm 3.59$ & \\
\hline \multicolumn{9}{|l|}{ Yaş } \\
\hline $18-25$ & $7.04 \pm 2.45$ & \multirow{4}{*}{$\begin{array}{c}\mathrm{F}=.551 \\
.647\end{array}$} & $4.52 \pm 1.86$ & \multirow{4}{*}{$\begin{array}{c}\mathrm{F}=2.652 \\
.055\end{array}$} & $2.74 \pm 1.21$ & \multirow{4}{*}{$\begin{array}{c}\mathrm{F}=.458 \\
.712\end{array}$} & $14.31 \pm 3.90$ & \multirow{4}{*}{$\begin{array}{c}\mathrm{F}=1.336 \\
.262\end{array}$} \\
\hline $26-34$ & $7.40 \pm 2.42$ & & $4.90 \pm 1.83$ & & $2.71 \pm 1.34$ & & $14.68 \pm 3.42$ & \\
\hline $35-42$ & $7.20 \pm 2.10$ & & $5.06 \pm 1.58$ & & $2.88 \pm 1.29$ & & $15.05 \pm 3.73$ & \\
\hline 43 ve üstü & $7.35 \pm 2.21$ & & $4.98 \pm 1.63$ & & $2.87 \pm 1.23$ & & $15.22 \pm 3.45$ & \\
\hline \multicolumn{9}{|l|}{ Eğitim durumu } \\
\hline İlköğretim & $7.31 \pm 2.38$ & \multirow{4}{*}{$\begin{array}{c}\mathrm{F}=1.818 \\
.243\end{array}$} & $5.00 \pm 2.09$ & \multirow{4}{*}{$\begin{array}{c}\mathrm{F}=2.637 \\
.050\end{array}$} & $2.75 \pm 1.00$ & \multirow{4}{*}{$\begin{array}{c}F=.769 \\
.512\end{array}$} & $15.05 \pm 3.38$ & \multirow{4}{*}{$\begin{array}{c}F=3.632 \\
.013\end{array}$} \\
\hline Lise & $7.35 \pm 2.21$ & & $4.70 \pm 1.78$ & & $2.67 \pm 1.31$ & & $14.61 \pm 3.38^{\mathrm{a}}$ & \\
\hline Üniversite & $7.02 \pm 2.38$ & & $4.61 \pm 1.72$ & & $2.78 \pm 1.26$ & & $14.82 \pm 3.64$ & \\
\hline Lisansüstü & $7.80 \pm 2.21$ & & $5.29 \pm 1.72$ & & $3.00 \pm 1.26$ & & $16.09 \pm 3.97 \mathrm{a}$ & \\
\hline \multicolumn{9}{|l|}{ Medeni durum } \\
\hline Bekar & $7.18 \pm 2.43$ & \multirow{2}{*}{$\begin{array}{c}\mathrm{t}=-.144 \\
.886\end{array}$} & $4.59 \pm 1.82$ & \multirow{2}{*}{$\begin{array}{c}\mathrm{t}=-1.891 \\
.059\end{array}$} & $2.70 \pm 1.22$ & \multirow{2}{*}{$\begin{array}{c}\mathrm{t}=-1.540 \\
.124\end{array}$} & $14.47 \pm 3.70$ & \multirow{2}{*}{$\begin{array}{c}\mathrm{t}=-1.526 \\
.128\end{array}$} \\
\hline Evli & $7.21 \pm 2.35$ & & $4.92 \pm 1.68$ & & $2.89 \pm 1.28$ & & $15.04 \pm 3.64$ & \\
\hline \multicolumn{9}{|l|}{ Çalışma durumu } \\
\hline Çalışan & $7.37 \pm 2.34$ & \multirow{4}{*}{$\begin{array}{c}\mathrm{F}=3.058 \\
. \mathbf{0 2 8}\end{array}$} & $4.98 \pm 1.76$ & & $2.89 \pm 1.24$ & & $15.24 \pm 3.56^{\mathrm{a}}$ & \\
\hline İş arayan & $7.63 \pm 2.10^{\mathrm{a}}$ & & $5.36 \pm 1.76^{a}$ & $F=6.152$ & $2.81 \pm 1.40$ & $F=1.577$ & $15.81 \pm 3.59 \mathrm{~b}$ & $F=7.563$ \\
\hline Öğrenci & $6.55 \pm 2.58^{a}$ & & $4.12 \pm 1.63^{\mathrm{a}}$ & .000 & $2.55 \pm 1.24$ & .195 & $13.24 \pm 3.73^{a, b}$ & .000 \\
\hline Ev hanımı & $7.43 \pm 2.21$ & & $4.72 \pm 1.71$ & & $2.81 \pm 1.28$ & & $14.97 \pm 3.42$ & \\
\hline Ekonomik durumu & & & & & & & & \\
\hline Kötü & $7.27 \pm 2.46$ & & $4.76 \pm 1.78$ & & $2.76 \pm 1.28$ & & $14.81 \pm 3.74$ & \\
\hline Orta & $7.12 \pm 2.40$ & $\begin{array}{c}\mathrm{F}=.212 \\
.809\end{array}$ & $4.70 \pm 1.70$ & $\begin{array}{c}\mathrm{F}=.357 \\
.700\end{array}$ & $2.84 \pm 1.22$ & $\begin{array}{c}\mathrm{F}=.203 \\
.816\end{array}$ & $14.66 \pm 3.53$ & $\begin{array}{c}\mathrm{F}=.165 \\
.848\end{array}$ \\
\hline İyi & $7.27 \pm 2.30$ & & $4.89 \pm 1.87$ & & $2.75 \pm 1.31$ & & $14.93 \pm 3.93$ & \\
\hline Kronik hastalık varlığı & & & & & & & & \\
\hline Evet & $7.50 \pm 2.94$ & $\mathrm{t}=-.786$ & $5.05 \pm 1.60$ & $\mathrm{t}=-1.046$ & $2.94 \pm 1.06$ & $\mathrm{t}=-.713$ & $15.50 \pm 2.90$ & $\mathrm{t}=-1.259$ \\
\hline Hayır & $7.17 \pm 2.43$ & .432 & $4.73 \pm 1.77$ & .296 & $2.78 \pm 1.27$ & .496 & $14.69 \pm 3.74$ & .209 \\
\hline Ruhsal sağlıkla ilgili konu & a ilgili olma & & & & & & & \\
\hline Evet & $7.20 \pm 2.42$ & $t=.048$ & $4.83 \pm 1.71$ & $\mathrm{t}=2.619$ & $2.84 \pm 1.23$ & $\mathrm{t}=2.388$ & $14.88 \pm 3.67$ & $t=2.096$ \\
\hline Hayır & $7.18 \pm 2.09$ & .962 & $4.00 \pm 2.09$ & .009 & $2.30 \pm 1.44$ & .017 & $13.48 \pm 3.51$ & .030 \\
\hline Ruhsal hastalığı olan bire & anıma & & & & & & & \\
\hline Hayır, tanımıyor & $6.96 \pm 2.41^{\mathrm{a}}$ & & $4.53 \pm 1.79 \mathrm{a}$ & & $2.79 \pm 1.71$ & & $15.25 \pm 3.61^{\mathrm{a}}$ & \\
\hline Evet, aileden, akrabamdan & $7.64 \pm 2.25$ & $\begin{array}{c}\mathrm{F}=.3 .810 \\
.023\end{array}$ & $5.12 \pm 1.60$ & $\begin{array}{c}\mathrm{F}=6.741 \\
.001\end{array}$ & $2.86 \pm 1.22$ & $\begin{array}{c}\mathrm{F}=.852 \\
.457\end{array}$ & $15.62 \pm 3.67$ & $\begin{array}{c}\mathrm{F}=8.032 \\
\mathbf{. 0 0 0}\end{array}$ \\
\hline Evet, arkadaşım, komşum & $7.73 \pm 2.43^{\mathrm{a}}$ & & $5.39 \pm 1.65^{\mathrm{a}}$ & & $3.00 \pm 1.09$ & & $16.12 \pm 3.46^{\mathrm{a}}$ & \\
\hline
\end{tabular}
a,b: fark yaratan alt gruplar

Katılımcıların RSOY ölçek toplam puan ortalaması $14.76 \pm 3.67$ 'dır. Ölçek toplam puan ortalaması, ölçekte yer alan 22 maddeye bölünmüş ve katılımcıların 1 soru için doğru yanıt 
ortalaması 0.670 olarak hesaplanmıştır. Bu doğrultuda düşük ortalamaya sahip ölçek maddeleri incelendiğinde RSOY-BO alt boyutunda 'Şizofreni'ye ve 'Depresyon'a yönelik, RSOY-İO alt boyutunda 'Hastalık oluşumu', 'Depresyon', 'İntihar', 'İyileşme' ve 'Tedavi' kavramlarına yönelik, RSOY-KO alt boyutunda ise 'İntihar' ve 'Hizmet kullanımı' na yönelik maddelerin olduğu görülmüştür (Tablo 3).

\section{Tablo 3}

RSOY ölçeğinden alınan ortalama puanın altında kalan ölçek maddeleri

\begin{tabular}{|c|c|c|}
\hline $\begin{array}{c}\text { Alt } \\
\text { Ölçek }\end{array}$ & Ortalama puanın altında kalan ölçek maddesi & $\begin{array}{c}\text { Puan } \\
(<0.670)\end{array}$ \\
\hline \multirow{2}{*}{ 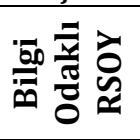 } & R2.Şizofreni olan insanlar gerçekte ortada olmayan şeyleri görürler. & 0.662 \\
\hline & $\begin{array}{l}\text { R5.Açılklanamayan fiziksel ağrı veya yorgunluk depresyon belirtisi } \\
\text { olabilir. }\end{array}$ & 0.662 \\
\hline \multirow{6}{*}{ 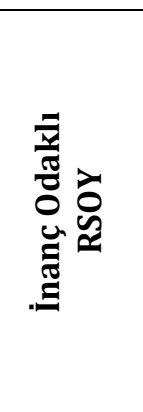 } & $\begin{array}{l}\text { R11.İnançlarına daha çok bağlı olan kişilerde ruh sağlığı bozukluğu } \\
\text { gelişmez. }\end{array}$ & 0.559 \\
\hline & R12.Ruh sağlığı hastalıkları kısa süreli hastalıklardır. & 0.662 \\
\hline & $\begin{array}{l}\text { R14.Depresyonda olan birine intihar düşüncesinin olup olmadığı } \\
\text { sorulmamalıdır. }\end{array}$ & 0.252 \\
\hline & R16.Ruh sağlığı hastalıklarından kurtulmak iyileşmekle aynı şeydir. & 0.180 \\
\hline & $\begin{array}{l}\text { R17.Bir kişi istediği zaman biriktirme hastalığını (eşya vs) } \\
\text { durdurabilir. }\end{array}$ & 0.419 \\
\hline & R18.Depresyonda olan kişi hiç tedavi edilmeden kendi bașına iyileșir. & 0.603 \\
\hline \multirow{2}{*}{ 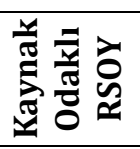 } & R20.Bir intiharı önlemek için nereyi arayacağımı biliyorum. & 0.543 \\
\hline & $\begin{array}{l}\text { R22.Yaşadığım yerdeki ruh sağlığı hastalıkları hizmet birimiyle nasıl } \\
\text { iletişim kurabileceğimi biliyorum }\end{array}$ & 0.623 \\
\hline
\end{tabular}

\section{TARTIŞMA, SONUÇ VE ÖNERİLER}

Gelişen sağlık sistemleri ve teknolojileriyle bireylerin sağlık sisteminden beklentileri değişirken, bireylere yüklenen sorumluluklar da değişmekte ve artmaktadır. Sağlık hizmetinden faydalanan bireylerin temel sağlık hizmetleri konusunda bilgi edinmesi, bu bilgiler ıșığında kendi sağlık sorumluluğunu alarak davranıșlarını yönlendirmesi beklenmektedir (Sezgin, 2013). Sağlık okuryazarlığının önemli bir bileșeni olan ruh sağlığı okuryazarlığı bu doğrultuda ruhsal sağlığa ilişkin farkındalığa sahip olma, tanı ve tedavi süreçlerine etkin katılma gibi sorumlulukları içermesi kadar ruh sağlı̆̆ına yönelik damgalamayla mücadeleyi de kapsayan bir önemli kavramdir.

Bir il merkezinde yașayan bireylerin ruh sağlığı okuryazarlığı düzeyinin incelendiği araştırmada RSOY ölçek toplam puan ortalamasının $14.76 \pm 3.67$ olduğu saptanmıştır. RSOY alt boyutları ve ölçek toplam puanında erkeklerin kadınlara göre, lise mezunu olanların lisansüstü eğitime sahip olanlara göre, öğrenci olanların olmayanlara göre daha düşük düzeyde ruh sağlığı okuryazarlığı olduğu saptanmıştır $(\mathrm{p}<.005)$. Ülkemizde 239 sağlık çalışanı ile yapılan bir 
çalışmada katılımcıların ölçek toplam puanının $16.96 \pm 3.30$ olduğu saptanmış, sağlık çalışanlarının yaşının, eğitim düzeyinin, medeni durumu ve mesleğinin önemli fark yarattı̆̆ı saptanırken, cinsiyetin fark yaratmadığı bildirilmiștir (Öztaş ve Aydoğan, 2021). Toplum bazında ruh sağlığı okuryazarlığını etkileyen değişkenler incelendiğinde erkek olma ve düşük eğitim düzeyine sahip olma ile düşük düzey ruh sağlığı okuryazarlığı arasında güçlü bir ilişki olduğu bulunmuştur (Kaneko ve Motohashi, 2007). Başka bir çalışmada kadın öğrencilerin ruh sağlığı okur yazarlığı düzeyinin erkeklerden daha yüksek olduğu bildirilmiştir (Miles vd., 2020). Erkelerin kadınlara göre ruh sağlığına yönelik olumlu tutumlarının da daha düşük olduğu belirlenmiştir (Lee vd., 2020a). Eğitim düzeyi yüksek olan katılımcıların, daha az eğitime sahip olanlardan daha yüksek ruh sağlı̆̆ı okuryazarlığı seviyesi gösterdiği, sağlık okuryazarlı̆̆ı ile ruh sağlığı okuryazarlığı arasında pozitif yönde anlamlı bir ilişki olduğu bulunmuştur (Lee, vd., 2020b). 520 üniversite öğrencisinin katıldığı bir çalışmada ise sağlık okuryazarlığının düşük düzeyde olduğu, yaş, cinsiyet, sigara içme durumu, çalışma yılı ve çalışma alanının önemli bir fark yarattı̆̆ı, kız öğrencilerin, sağlıkla ilgili fakülte öğrencilerinin ve sigara içmeyenlerin daha yüksek sağlık okuryazarlığına sahip olduğunu ortaya koymuştur (Rababh, vd., 2019). Araștırma bulguları alanyazın ışığında değerlendirildiğinde katılımcıların ruh sağlı̆̆ı okuryazarlığı düzeyinin yüksek olduğu, bunun da katılımcıların bir il merkezinde yaşama, eğitim düzeyinin yüksek olması ve çoğunluğunun kadın olması ile ilgili olduğu söylenebilir. Yine araştırmada erkeklerin daha düşük ruh sağlığı okuryazarlığına sahip olmalarının, ruhsal hastalıklara yönelik olumsuz tutumlarından kaynaklandığı, eğitim düzeyi yükseldikçe ruh sağlığı okuryazarlığının artmasının ise eğitimöğretim programları içinde verilen ruh sağlığı ve hastalıklarına yönelik bilgiler nedeniyle olduğu düşünülmektedir. Öğrenci olan katılımcıların diğerlerine göre eğitim süreçlerini tamamlamamış olması ya da sağlıkla ilgili olmayan bir alanda eğitim görmeye devam etmesinin ruh sağlığı okuryazarlı̆̆ının düşük düzeyde olmasına neden olduğu söylenebilir.

Araştırma kapsamında ele alınan katılımcıların ruh sağlı̆̆ıyla ilgili konulara ilgisiz olma ve ruhsal sorunu olan bireyleri tanımama durumlarının ruh sağlığı okuryazarlığını olumsuz etkilediği ve puan ortalamalarının düşük olduğu bulunmuştur $(\mathrm{p}<.005)$. Ruhsal konulara ilgili olma ya da ruhsal hastalığı olan bireyi tanıma durumları bu konuya yönelik bilgi düzeyini artırmada etkili olabilmektedir. Miles ve arkadaşları (2020) tarafından 1213 üniversite öğrencisi ile yapılan bir çalışmada klinik psikoloji ile ilgili en az bir ders almış, psikoloji ve uygulamalı sağlık bilimleri alanlarında eğitim gören, kişisel, aile ya da akran geçmişi yoluyla psikolojik bozukluklarla daha fazla deneyime sahip olanların ve ruh sağlığı konularını tartışmaya açık aileleri bulunan öğrencilerin ruh sağlı̆̆ı okuryazarlığının daha yüksek olduğunu bulmuştur. Ruhsal hastalığı olan bireye bakım veren aile üyelerinin 1993 ile 2016 yılları arasındaki 23 yıllık bir dönemdeki ruh sağlığı okuryazarlığı düzeyini karşılaştırmak için yapılan bir çalışmada bakım veren aile üyelerinin ruh sağlığı okuryazarlığı düzeyinin artış yönünde önemli bir pozitif eğilim 
gösterdiği saptanmıştır (Mehrotra, vd., 2018). Kanada'da 3047 katılımcı ile yapılan bir çalışmada depresyona yönelik ruh sağlığı okuryazarlığı düzeyi araştırılmış, depresyon vakasını tanıma, tedavi konusunda sağlık profesyonelleri ile anlaşma, depresyonlu bireyle kişisel temas ve damgalanma arasındaki ilişkilerin ruh sağlığı okuryazarlığını etkilediği gösterilmiştir (Wang ve Lai, 2008). Araştırma bulgusunun alanyazınla uyumlu olduğu görülmektedir. Ruhsal hastalığı olan bireyin aile üyesinden, akrabasından, arkadaşından ya da komşusundan olması ile ruhsal hastalığın tanınması, hastalık belirtileri ve tedavi yöntemlerine yönelik kişisel deneyimin artması, ek olarak ruhsal hastalığı olan yakınına yardımcı olmak için ruhsal hastalıklara yönelik araştırma yapılması gibi durumların ve ruhsal sağlıkla ilgili konulara ilgi duymanın doğal bir sonucu olarak ruh sağlığı okuryazarlığının arttığı düşünülebilir.

Özellikle toplumsal düzeyde hizmetlerin planlamasında toplumdaki bireylerin gereksinimlerinin belirlenmesi ve önceliklerin bu doğrultuda oluşturulması önemlidir. Araştırmada ölçek maddeleri ortalama puanları değerlendirildiğinde 'Şizofreni', 'Depresyon', 'Hastalık oluşumu', 'İntihar', 'İyileşme', 'Tedaviler' ve 'Hizmet kullanımına' yönelik maddelerin diğerlerine göre daha düşük ortalamaya sahip olduğu görülmüştür. Depresyona yönelik ruh sağlığı okuryazarlığı düzeyini araştıran bir çalışmada katılımcıların \%25.2'si depresyon hakkında yetersiz bilișe, \%12.5'i depresyona karşı yetersiz tutuma sahip olduğu ve \%13.1'inin intiharı doğal kabul ettiğini göstermiştir (Wang ve Lai, 2008). Avusturalya'da hemşirelik öğrencileri ile yapılan bir çalışmada katılanların çoğu $(\% 66,7)$ farklı ruhsal hastalık türleri, tedavileri, ruh sağlığı üzerindeki damgalanmanın nasıl azaltılacağı, ruhsal hastalığı olan kişilere nasıl bakılacağı ve onlarla nasıl iletişim kurulacağı hakkında daha fazla bilgi ihtiyacı olduğunu bildirmiștir (Saito ve Creedy, 2021). Ruhsal hastalıklara yönelik mitlerin fiziksel hastalıklara yönelik mitlerden daha fazla olduğu, şizofrenin de ruhsal hastalıklara içinde en fazla mite ve yanlış bilgilere sahip olan hastalık olduğu bildirilmektedir (Vimalanathan ve Furnham, 2019; Sungur, 2020). Mitlerin toplum içinde yaygın olması ve nesilden nesile aktarılmasıyla, hastaların anlaşılması ve yardım arayışı engellemekte, damgalamanın etkisi ile tanı ve tedavi süreci olumsuz etkilemektedir (Sungur, 2000). Yine bu tarz mitlerin depresyon ve intihara yönelik olarak da oldukça yaygın olduğu ve bu durumun ölçekte verilen yanıtlarla uyumlu olduğu görülmektedir. İntihar girişiminde bulunan bireyin dikkat çekmek istediği ve intihar niyetinin sorgulanmasının intihar niyetini artıracağına dair mitler, intihar niyetinde olan bireye yardımı güçleştirmekte ve intiharla mücadeleyi olumsuz etkilemektedir (Bowers, vd., 2010). Araştırmada depresyona yönelik bilgi eksikliği, intiharın sorgulanması, intihar için nereyi arayacağını bilmemek ve ruhsal hizmet kullanımı konusunda bilgi eksikliğinin de geliştirilmesi gereken alanlar olduğu saptanmıștır. $\mathrm{Bu}$ doğrultuda kökenini eski çağlardan alan ruhsal hastalıklara yönelik mitlerin ve yanlış inançların etkisinin hala devam ettiği ve ruh sağlığı okuryazarlığını olumsuz etkilediği söylenebilir. 
Sonuç olarak bir il merkezinde yaşayan bireylerin ruh sağlığı okuryazarlığı düzeyinin incelendiği bu araştırmada ruh sağlığı okuryazarlığının yüksek düzeyde olduğu, sosyodemografik değişkenlerden etkilendiği ve özellikle şizofreni, depresyon ve intihar gibi konular hakkında toplumun desteklenmesi gerektiği saptanmıştır. Toplumun ruh sağlığı okuryazarlığının incelendiği farklı popülasyonlara yönelik çalışmaların yapılması önerilmektedir.

Araştırmanın sınırlılıkları olarak verilerin online form ile toplanması nedeniyle kişisel beyana bağlı bilgilerin toplanması, online yöntemin il merkezinde yaşayan ve akıllı telefonu olmayan bireylerin katılımını sınırlaması olarak sıralanabilir. 


\section{KAYNAKÇA}

Baştürk, S., \& Taştepe, M. (2013). Evren ve örneklem. Bilimsel Araştırma Yöntemleri. Vize Yayıncılık.

Bjørnsen, H. N., Eilertsen, M., Ringdal, R., Espnes, G. A., \& Moksnes, U. K. (2017). Positive mental health literacy: development and validation of a measure among Norwegian adolescents. BMC Public Health, 17(1), 717-727. https://doi.org/10.1186/s12889-017-4733-6

Bowers, L., Banda, T., \& Nijman, H. (2010). Suicide inside: a systematic review of inpatient suicides. The Journal of Nervous and Mental Disease, 198(5), 315-328. https://doi.org/10.1097/NMD.0b013e3181da47e2

Corrigan, P. W., Powell, K. J., \& Al-Khouja, M. A. (2015). Examining the Impact of Public Service Announcements on Help Seeking and Stigma: Results of a Randomized Controlled Trial. The Journal of Nervous and Mental Disease,203(11), 836-842. https://doi.org/10.1097/NMD.0000000000000376

Evans-Lacko, S., Malcolm, E., West, K., Rose, D., London, J., Rüsch, N., Little, K., Henderson, C., \& Thornicroft, G. (2013). Influence of Time to Change's social marketing interventions on stigma in England 2009-2011. The British Journal of Psychiatry Supplement, 202(S55), 7788. https://doi.org/10.1192/bjp.bp.113.126672

Göktaş, S., Işıklı, B., Önsüz, M., Yenilmez, Ç., Metintaş, S. (2019). Ruh Sağlığı Okuryazarlığı Ölçeği'nin (Rsoy Ölçeği) Türkçe Geçerlilik ve Güvenilirliğinin Değerlendirilmesi. Konuralp Medical Journal, 11(3), 424-431. https://doi.org/10.18521/ktd.453411 https://doi.org/10.1186/s12889-019-7781-2

Jorm, A. F. (2012). Mental health literacy: empowering the community to take action for better mental health. The American Psychologist, 67(3), 231-243. https://doi.org/10.1037/a0025957

Jorm, A. F., Korten, A. E., Jacomb, P. A., Christensen, H., Rodgers, B., \& Pollitt, P. (1997). Mental health literacy: A survey of the publics ability to recognise mental disorders and their beleifs about the effectiveness of treatment. Medical Journal of Australia, 166(4), 182-186.

Jung, H., Von Sternberg, K., \& Davis, K. (2016). Expanding a measure of mental health literacy: Development and validation of a multicomponent mental health literacy measure. Psychiatry Research, 243, 278-286. https://doi.org/10.1016/j.psychres.2016.06.034

Kaneko, Y., \& Motohashi, Y. (2007). Male gender and low education with poor mental health literacy: a population-based study. Journal of Epidemiology,17(4), 114-119. https://doi.org/10.2188/jea.17.114.

Karasar, N. (2017). Bilimsel Araştırma Yöntemi. Nobel Yayınevi.

Kılıç, C. (1998). Erişkinlerle ilgili sonuçlar. Türkiye Ruh Sağlığı Profili: ana rapor (Erol N, Kılıç C, Ulusoy M, Keçeci M, Şimşek Z, Ed.). Sağlık Bakanlığı Yayınları.

Kutcher, S., Wei, Y., \& Coniglio, C. (2016). Mental Health Literacy: Past, Present, and Future. Canadian Journal of Psychiatry. Revue Canadienne de Psychiatrie, 61(3), 154-158. https://doi.org/10.1177/0706743715616609.

Lee, H. Y., Hwang, J., Ball, J. G., Lee, J., \& Albright, D. L. (2020b). Is health literacy associated with mental health literacy? Findings from Mental Health Literacy Scale. Perspectives in Psychiatric Care, 56(2), 393-400. https://doi.org/10.1111/ppc.12447

Lee, H. Y., Hwang, J., Ball, J. G., Lee, J., Yu, Y., \& Albright, D. L. (2020a). Mental Health Literacy Affects Mental Health Attitude: Is There a Gender Difference?.American Journal of Health Behavior, 44(3), 282-291. https://doi.org/10.5993/AJHB.44.3.1 
Li, H. (2012). Mental health literacy, stigma, and early intervention. Elsevier Science BV.

Mehrotra, K., Nautiyal, S., \& Raguram, A. (2018). Mental health literacy in family caregivers: A comparative analysis. Asian Journal of Psychiatry, 31, 58-62. https://doi.org/10.1016/j.ajp.2018.01.021

Miles, R., Rabin, L., Krishnan, A., Grandoit, E., \& Kloskowski, K. (2020). Mental health literacy in a diverse sample of undergraduate students: demographic, psychological, and academic correlates. BMC Public Health, 20(1), 1699-1712. https://doi.org/10.1186/s12889-02009696-0

Naidu, A. (2008). Health literacy. Whitireia Nursing Journal, 15, 39-46.

Özel, Y. (2018). Ruh Sağlığı Okuryazarlı̆̆ı. Akademik Sosyal Araştırmalar Dergisi, 77, 380-387.

Öztaş, B., \& Aydoğan, A. (2021). Sağlık profesyonellerinin ruh sağlı̆̆ı okuryazarlık düzeylerinin belirlenmesi. Psikiyatri Hemşireliği Dergisi. https://doi.org/10.14744/phd.2021.43265

Rababah, J. A., Al-Hammouri, M. M., Drew, B. L., \& Aldalaykeh, M. (2019). Health literacy: exploring disparities among college students. BMC Public Health, 19(1), 1401-1414. https://doi.org/10.1186/s12889-019-7781-2

Reavley, N.J., Jorm, A.F. (2011). National survey of mental health literacy and stigma. Canberra: Department of Health and Ageing.

Saito, A. S., \& Creedy, D. K. (2021). Determining mental health literacy of undergraduate nursing students to inform learning and teaching strategies. International Journal of Mental Health Nursing, 30(5), 1117-1126. https://doi.org/10.1111/inm.12862

Sezgin, D. (2013). Sağlık okuryazarlığını anlamak. Galatasaray Üniversitesi İletişim Dergisi, 72-92. Sungur, M. Z. (2000). Şizofreni: Mitler ve gerçekler. Klinik Psikiyatri Dergisi, 3(1), 5-12.

Türkiye İstataistik Kurumu. (2021, Şubat). Kırşehir Nüfusu 2020. TÜİK Kurumsal (tuik.gov.tr)

Vimalanathan, A., \& Furnham, A. (2019). Comparing physical and mental health literacy. Journal of Mental Health (Abingdon, England), 28(3), 243-248. https://doi.org/10.1080/09638237.2018.1466050

Wang, J., \& Lai, D. (2008). The relationship between mental health literacy, personal contacts and personal stigma against depression. Journal of Affective Disorders, 110(1-2), 191-196.

Yap, M. B., Reavley, N. J., \& Jorm, A. F. (2012). Associations between awareness of beyondblue and mental health literacy in Australian youth: Results from a national survey. The Australian and New Zealand journal of Psychiatry, 46(6), 541-552. https://doi.org/10.1177/0004867411435288 


\section{EXTENDED ABSTRACT}

\section{Introduction}

Mental health literacy, which is a component of health literacy, is an important determinant of mental health with its potential to improve health individually and socially (Ozel, 2018). Mental health literacy is a concept that expresses "knowledge and beliefs that help to recognize, manage or prevent mental disorders" (Jorm et al., 1997). With a perspective that covers the health policies of the country, it is aimed that the individuals who make up the society have information about the prevention, recognition, treatment and rehabilitation of mental illnesses, and that the behavior of seeking help is reduced by reducing stigma (Reavley and Jorm, 2011). Patients with low health literacy may be disadvantaged in seeking help because they may not understand the information well or receive less preventive health care (Naidu, 2008). It is reported that only half of individuals with any mental illness use mental health services (Bjensan et al., 2017), and this results in the chronicity and aggravation of mental illnesses due to seeking help in the advanced stage of the disease (Kutcher et al., 2016; Li, 2012).

The first step is to define the knowledge, beliefs and attitudes of the individuals who make up the community towards mental problems in the planning of services and policies for community mental health. Thus, by making special interventions according to variables such as the age, gender and place of residence of the individuals, the mental health literacy of the individuals and therefore the society will be increased. Although the concept of mental health literacy, which was first defined in 1997, was started to be examined in western countries in earlier periods, it has come to the fore in our country in recent years and the scarcity of research in this direction is at a remarkable level. In the literature review, it was seen that there is a research for healthcare professionals in our country apart from scale development studies (Öztas and Aydoğan, 2020). It will be possible to identify support groups and establish priorities through research on mental health literacy.

\section{Method}

The research is of descriptive type. The population of the research consists of adult individuals between the ages of 18-65 living in the city center of Kırşehir. 383 people constituted the sample of the research with $95 \%$ confidence level and $5 \%$ confidence interval by using a specific population sample calculation. Inclusion criteria for the research; being between the ages of 18-65, living in the city center and agreeing to participate in research. Due to the Covid 19 pandemic, the data were collected using the online platform, using the random snowball method. Research data were collected with the Introductory Information Form and the Mental Health 
Literacy Scale (MHLS). Descriptive statistics were used to present the data, Independent t-test for analysis, One-way ANOVA and Tukey test for further analysis were used.

\section{Results}

When the distribution of the individuals participating in the research according to their descriptive characteristics is examined, $54.6 \%$ of them are female, $34.5 \%$ are between the ages of $18-25$, and the average age is $33.84 \pm 11.56,59.8 \%$ are university graduates, $50.7 \%$ are single. It was determined that the mean mental health literacy score of individuals was $14.76 \pm 3.67$. In the MHLS sub-dimensions and the total score of the scale, it was determined that men had lower mental health literacy than women, those who were high school graduates than those with postgraduate education, and those who were students compared to those who did not have a lower level of mental health literacy $(\mathrm{p}<0.05)$. It was found that the participants' indifference to mental health issues and not knowing individuals with mental health problems negatively affected their mental health literacy and their average score was low $(\mathrm{p}<.005)$. When the mean scores of the scale items were evaluated in the study, it was seen that the items for "Schizophrenia", "Depression", "Illness formation", "Suicide", "Recovery", "Treatments" and "Service use" had a lower average than the others.

\section{Discussion \& Conclusion}

In the MHLS sub-dimensions and the total score of the scale, it was determined that men had lower mental health literacy than women, those who were high school graduates than those with postgraduate education, and those who were students compared to those who did not have a lower level of mental health literacy $(\mathrm{p}<.005)$. In a study conducted with 239 healthcare professionals in our country, the scale total score of the participants was found to be $16.96 \pm 3.30$, and it was reported that the age, education level, marital status and profession of the healthcare professionals made a significant difference, while gender did not make a difference (Öztaş and Aydoğan, 2020). When the variables affecting mental health literacy on a community basis were examined, it was found that there was a strong relationship between being male and having a low education level and low mental health literacy (Kaneko \& Motohashi, 2007). In another study, it was reported that the mental health literacy level of female students was higher than that of males (Miles et al., 2020). When the research findings are evaluated in the light of the literature, it can be said that the mental health literacy level of the participants is high, which is related to the fact that the participants live in a city center, have a high education level, and the majority of them are women. Again in the study, it is thought that the fact that men have lower mental health literacy is due to their negative attitudes towards mental illnesses, and that the increase in mental health literacy as the education level increases is due to the information on mental health and diseases given in the education-training programs. It can be said that the fact that the participants, who are 
students, have not completed their education process or that they continue to study in a field that is not related to health, causes a low level of mental health literacy.

As a result, in this study, which examined the mental health literacy level of individuals living in a city center, it was determined that mental health literacy was at a high level, affected by sociodemographic variables, and the society should be supported especially about issues such as schizophrenia, depression and suicide. In this direction, it is recommended to carry out advanced studies to improve the mental health literacy of the society. 